\title{
Decontamination Efficiency of Phenylamine using Foam coupled Acidic Spray
}

\author{
Wang Shouzhong ${ }^{1,2}$, Zhou Zhen ${ }^{1,2}$, Zhang Tong ${ }^{1,2, *}$, Fang Xiaojun ${ }^{1,2}$, and Miao Chaoyang ${ }^{1}$ \\ ${ }^{1}$ Beijing Special Engineering Design and Research Institute, Beijing 100028 China \\ ${ }^{2}$ State Key Laboratory of Technologies in Space Cryogenic Propellants, Beijing 100028 China
}

\begin{abstract}
A sudden leak of phenylamine is an urgent environmental issue due to its liquidity and volatility. To overcome this difficulty, the decontamination efficiency of spray, foam, and activated carbon to phenylamine was explored using simulated leak box. Furthermore, a new decontamination method of foam coupling with acidic spray was proposed to decontaminate phenylamine. Its decontamination efficiency for phenylamine gas was up to $90 \%$ after 3 min adsorption at 3:1 mass ratio and phenylamine liquid was solidified quickly.
\end{abstract}

\section{Introduction}

Aniline $\left(\mathrm{C}_{6} \mathrm{H}_{5} \mathrm{NH}_{2}\right)$, the simplest primary aromatic amine, was first prepared from indigo through pyrolysis distillation by Otto Unverdorben ${ }^{[1]}$. Aniline is a highly toxic substance, and it can bind with hemoglobin to form methemoglobin, and then decrease the hemoglobin's ability to bind to oxygen; finally, it will result in animal poisoning. Therefore, it has been listed as an environmental priority pollutant ${ }^{[2-4]}$.

Aniline is an important chemical raw material. With the increasing demand for aniline in China, more leakage accidents have taken place during processing, storage and transportation ${ }^{[5-7]}$. In 2005, the explosion of aniline workshop in PetroChina Jilin Petrochemical Company caused pollution of Songhua River; in 2006, the explosion of waste acid tank in waste acid concentration unit of aniline plant of Lanzhou Petrochemical caused a fire; in 2007, the aniline plant of Jiangsu Myland occurred an explosion accident; in 2008, an aniline tank car in Dalian occurred an overturning and leakage accident; in 2010, an aniline poisoning accident occurred in a waste recycling shop in Xiaoshan District of Hangzhou City; and in 2012, a conveying hose in the aniline tank area of Tianji Fangyuan Company of Changzhi City, Shanxi Province was damaged, and 8.68 tons of aniline leaked.

Aniline leakage accidents occur frequently, but the corresponding technical level of leakage emergency disposal is relatively lagging. The contradiction in between is increasingly prominent. For the small leakage of aniline, the most common method is to absorb or adsorb with sand or other non-combustible materials. When large number of aniline leaks, it is necessary to build a dike or dig a hole to hold it, or spray water or foam to cool and dilute steam, and protect on-site personnel. Transfer it to a tank truck or special collector with a pump for recycling or disposal at a waste disposal site.

Existing disposal methods for aniline mainly include physical adsorption, photocatalytic oxidation, chlorine dioxide oxidation, electrochemical method, biology, etc. ${ }^{[8-12]}$, and most of them are used for disposing wastewater containing a small amount of aniline (generally in tens of milligrams per liter) rather than the elimination of pure aniline, so they are not suitable for emergency disposal of leakage of large quantities of pure aniline. It is difficult to apply them in actual aniline leakage accidents.

Due to the fluidity and volatility of aniline, there are liquid and gas hazards when it leaks. Therefore, we shall rapidly reduce the concentration of aniline vapor in the air, to provide conditions for emergency rescue workers to enter the site; in addition, we shall also achieve the rapid curing of liquid aniline, to prevent its flow and avoid the expansion of hazard areas. The curing of aniline can also reduce its volatility and the harm of aniline vapor.

In view of the alkalinity and reducing property of aniline ${ }^{[7,13,14]}$, it is proposed to adopt the disposal idea of foam coupled acidic spray. With the addition of acidic disposal agent and oxidant, aniline vapor and liquid can be converted into aniline salt through chemical reaction. Then foam can be used to cover the treated product, to inhibit the re-evaporation of aniline vapor, and finally, it can keep the aniline vapor concentration below the safe concentration for a long time. The reduction of the aniline leakage hazard as much as possible can provide necessary conditions for subsequent rescue and disposal.

\section{Test method}

\subsection{Preparation of the disposal agent}

\footnotetext{
* Corresponding author: 1164177746@qq.com
} 


\subsubsection{Water mist disposal agent}

Preparation method I: Dissolve at least one of $\mathrm{H}_{3} \mathrm{PO}_{4}$, $\mathrm{HCl}$ and $\mathrm{H}_{2} \mathrm{SO}_{4}$ in water at the concentration of 15 to 40 wt $\%$, add 0 to 8.0 wt $\%$ oxidants such as $\mathrm{H}_{2} \mathrm{O}_{2}$ and $\mathrm{KMnO}_{4}$, and add 0.01 to $0.5 \mathrm{wt} \%$ tactile compounds (polysaccharides, sodium polyacrylate, etc.) to prepare a colorless and transparent solution.

Preparation method II: Dissolve at least one of $\mathrm{KH}_{2} \mathrm{PO}_{4}, \mathrm{~K}_{2} \mathrm{HPO}_{4}, \mathrm{NaH}_{2} \mathrm{PO}_{4}$ and $\mathrm{Na}_{2} \mathrm{HPO}_{4}$ in water at the concentration of 15 to $30 \mathrm{wt} \%$, and add 0.01 to 1.0 $\mathrm{wt} \%$ softener (medium strength solid acid, etc.) to prepare a colorless and transparent solution.

\subsubsection{Test equipment and procedure}

The simulation test device for emergency disposal of aniline leakage is shown in Figure 1. The simulated leakage tank is made of colorless transparent glass with a size of $500 \mathrm{~mm} \times 500 \mathrm{~mm} \times 500 \mathrm{~mm}$. The inlet of the disposal agent injection system is in the middle of the tank top. A small hole in the side of tank is used for extracting gas sample for concentration detection.

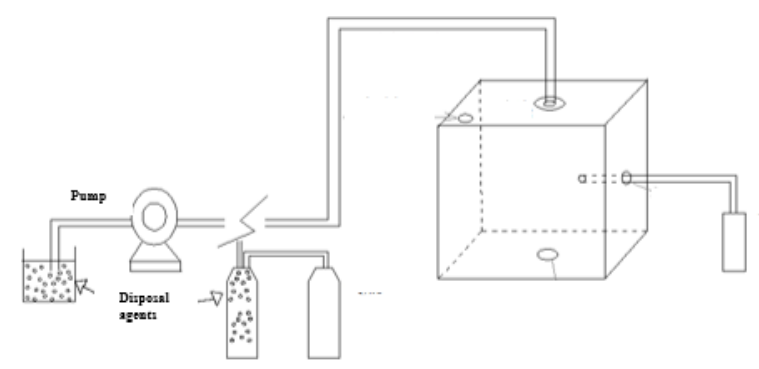

Fig. 1. Schematic diagram of the experiment

During the test, add $250 \mathrm{~mL}$ of aniline (analytical pure) to the tank each time. With time going on, the aniline gradually volatilized. The change trend of the concentration of aniline vapor in the simulated leakage tank is shown in Figure 2. After the aniline leaked, the concentration of aniline vapor reached the concentration of acute poisoning in human body at $2 \mathrm{~min}$, and reached a relatively stable state after $60 \mathrm{~min}$. Therefore, the initial concentration of aniline vapor in the tank was determined after $60 \mathrm{~min}$ of aniline volatilization in each test. Different kinds and doses of disposal agents were added, and after stopping addition, the concentration of aniline vapor in the simulated leakage tank was measured at a certain interval, and then the state change of liquid aniline at the bottom of tank was observed. The determination of aniline concentration was carried out by using the aniline compound-N-(1-naphthyl) ethylenediamine azo spectrophotometry (GB/T118891989), and the $\mathrm{R}^{2}$ of standard curve was 0.9978, indicating a good correlation.

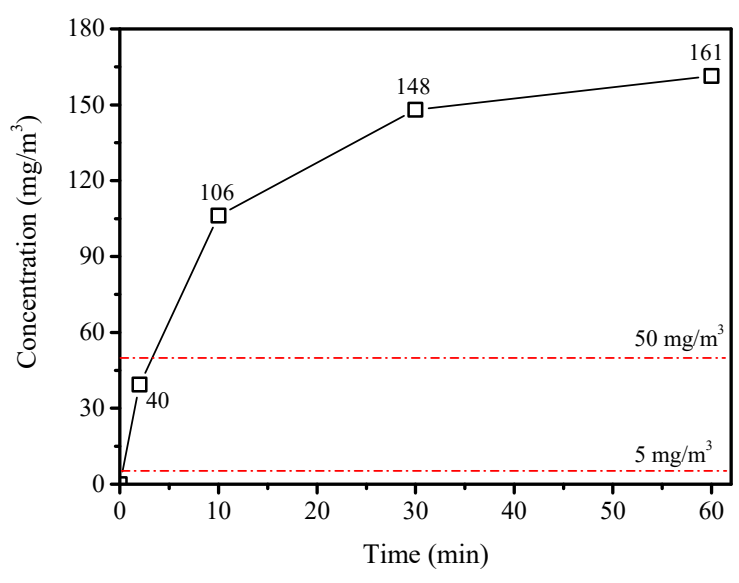

Fig. 2. Effect of reaction time on phenylamine concentration in simulated leak box

\section{Result and discussion}

\subsection{Decontamination of phenylamine using a single disposal agent}

\subsubsection{Disposal with water mist}

Firstly, the aniline disposal effect of water mist was discussed. The average diameter of water mist droplets was $140 \mu \mathrm{m}$ and the flow rate was $360 \mathrm{~mL} / \mathrm{min}$. The disposal was carried out under the condition that the dosage of disposal agent was 3 times of the amount of aniline leaked. The results are shown in Figure 3.

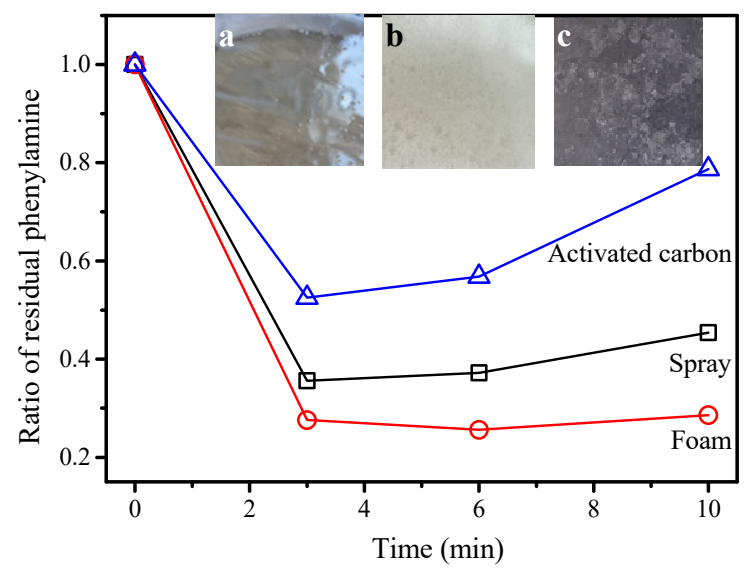

Fig. 3. Decontamination efficiency of phenylamine by spray (a), foam (b), and activated carbon (c) and their morphology (inset)

As shown in Figure 3, the elimination rate of aniline vapor by pure water mist disposal agent was only $47.5 \%$. With the extension of time, the concentration of aniline rose rapidly, and reached $56.8 \%$ of the initial concentration at $6 \mathrm{~min}$, and later at $10 \mathrm{~min}$, it reached $78.7 \%$ of the initial concentration. When the water mist settled to the bottom of tank, it could not be completely miscible with liquid aniline, and the liquid surface appeared as oil beads (as shown in Figure 3a).

Since the solubility of aniline in water is very small, the use of a single water mist can only reduce the 
concentration of aniline vapor, and the reduction of the concentration of aniline vapor is limited. The water mist cannot cure the liquid aniline at the bottom of tank. The settlement of large amount of water mist and the increase in liquid volume may even cause an increase in the range of aniline flow and diffusion, resulting in a greater degree of hazard.

\subsubsection{Disposal with foam}

The foam liquid containing two kinds of compound surfactants SDS and SDBS was selected. Store foam liquid in the foam tank to generate foam through the foam generator, and inject foam into the simulated leakage tank to evaluate the disposal effect.

The change in concentration of aniline vapor in the tank after application of the foam disposal agent is shown in Figure 3. After application, the elimination rate of aniline vapor by foam agent was about $72.4 \%$, but the concentration of aniline vapor gradually decreased with time, and there was no rise like that in elimination by water mist. At $6 \mathrm{~min}$, the elimination rate increased to $74.5 \%$. At $10 \mathrm{~min}$, the foam partially digested and the elimination rate decreased slightly $(70.8 \%)$. At the same time, it was observed that the liquid aniline at the bottom of tank did not solidify and was still in the flowing state (Figure 3b). In actual leakage, there is still the possibility that the flow diffusion will lead to a larger area of soil or water pollution. Foam is a group of bubbles surrounded by water film with large specific surface area and higher aniline vapor capture efficiency than that of water mist. Similarly, water film in the foam only adsorbs and dilutes the aniline vapor, and its elimination rate failed to meet the requirements; however, the foam had a good effect on suppressing the volatilization of aniline vapor, so it can prevent the concentration of aniline vapor in the tank from rising for a long time.

\subsubsection{Disposal with activated carbon}

Activated carbon powder is also a commonly used disposal agent in the emergency disposal of aniline leakage. In Figure 3, the elimination rate of aniline by activated carbon powder was $64.4 \%$, which increased slightly with time. After the settlement of activated carbon powder, it was mixed with the aniline liquid at the bottom of tank to form a slurry (Figure 3c). The mixture could still flow partially, but its fluidity was poor.

Activated carbon is a good adsorbing material with a well-developed pore structure and a large specific surface area. After the activated carbon is applied to the tank, the aniline vapor can be adsorbed and then settled to the bottom of tank to reduce the concentration of aniline vapor. However, the adsorption capacity of activated carbon is limited. Under the condition that large number of aniline leaks to produce a large amount of aniline vapor, the elimination rate of aniline vapor is limited. On the other hand, the adsorption of aniline vapor by activated carbon is mainly physical adsorption, and the adsorption rate is easily affected by changes in external conditions such as temperature and pressure change. For example, the temperature rise may cause desorption and the aniline vapor will escape again, causing secondary damage. In addition, after the activated carbon powder is sprayed into the leakage space, a thick dust will be formed to cause visual obstacles in the space, which has a certain impact on personnel evacuation and rescue. Therefore, in its actual use for emergency disposal, activated carbon is mainly thrown into the leaked aniline liquid to adsorb and solidify aniline, and is generally not used for the elimination of aniline vapor.

\subsection{Decontamination of phenylamine using foam coupled water mist}

In view of the shortcomings of the above three traditional disposal methods, based on the physicochemical properties of alkalinity and reducing properties of aniline, a scheme for emergency disposal of aniline leakage using foam coupled water mist was proposed: first spraying multi-component water mist disposal agent containing inorganic acid and thixotropic gel to convert and solidify the aniline vapor and aniline liquid, and then spraying the foam to cover and inhibit the re-evaporation of aniline vapor.

Figure 4 shows the concentration change of aniline vapor in the tank after the combined disposal using two kinds of multi-component water mists and foams. AW-1 is a multi-component water mist containing sulfuric acid, and $\mathrm{AW}-2$ is a multi-component water mist containing phosphoric acid. The decontamination rate of both reached more than $90 \%$ at $3 \mathrm{~min}$ and the aniline vapor concentration did not increase significantly at $10 \mathrm{~min}$. Unlike pure water mist disposal, after the combined disposal, the decontamination rate caused no concentration increase with time. This is mainly due to two reasons: on the one hand, the gradual sedimentation of water mist leads to a corresponding decrease in the concentration of aniline vapor in the air; on the other hand, due to the coverage and inhibition of foam, it is difficult for aniline vapor at the bottom to evaporate out of the foam layer again, resulting in the gradual decrease of aniline vapor concentration in the tank.

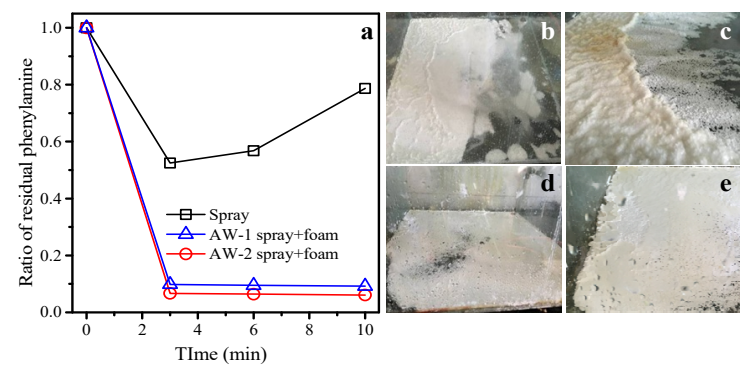

Fig. 4. Decontamination efficiency of phenylamine by foam coupled acidic spray (a) and their morphology in the box (b-c: AW-1, d-e: AW-2)

When the water mist disposal agent was added to the tank, white precipitation appeared immediately in the aniline liquid at the bottom of tank; then the precipitation gradually turned brown. This is mainly due to the 
reaction of aniline with acid to form aniline salt solids. Figure $4 \mathrm{~b}$-e shows the state changes of aniline at the bottom of tank after the application of AW-1 and AW-2 water mist disposal agents. As shown in Figure 4b-c, the liquid aniline at the bottom solidified immediately after application of AW-1 to form granular white solids.

Like AW-1, AW-2 disposal agent reacted immediately after contact with the liquid aniline to form white plate solids (Figure 4d) and there was no liquid flow in the tank. The foam then applied completely covered the bottom (Figure 4e). Although the foam thickness decreased with time, it could maintain a complete shape within $1 \mathrm{~h}$ without damage at the bottom. The concentration of aniline vapor in air decreased by $91.2 \%$ at $3 \mathrm{~min}$. The decontamination rates of $\mathrm{AW}-1$ and AW-2 disposal agents were similar. AW-1 disposal agent containing sulphuric acid was more acidic and accompanied by a certain degree of oxidation, considering this, the safer phosphate-based AW-2 disposal agent was selected.

\section{Conclusion}

Summary, if mass ratio of the disposal agent and the leaked aniline is $3: 1$, the single water mist, foam or activated carbon have poor decontamination effect of aniline; however, the combined disposal using foam coupled water mist can realize the effective decontamination of leaked aniline. The decontamination rate of aniline vapor can reach more than $90 \%$ within 3 min, and the aniline liquid can be rapidly solidified, which provides the necessary conditions for subsequent rescue and disposal.

\section{Acknowledgments}

We are thankful for the financial support from the National Science \& Technology Pillar Program of China (2015BAK37B00) and the Key Science and Technology Innovation Project in Shandong Province (2019JZZY020503).

\section{References}

1. W. Wang, Z. Zhuang, R. Bai, Chem. Propellants Polym. Mater., 8 (2019).

2. A. Lu, Coal Chem. Ind., 33 (2005).

3. Y. Liu, L. Jiang, H. Jia, J. Huaihai Inst. Technol., 18 (2009).

4. L. Lu, X. Li, X. Shi, Fire Sci. Technol., 38 (2019).

5. X. Zhang, L. Lu, H. Yi, J. Chin. People's Chinese People's Armed Police Force Acad., 29 (2013).

6. Z. Huang, M. Feng, J. Peng, Dyest. Color., 55 (2018).

7. R. Chen, Dyest. Color., 3 (2016).

8. J. Ge, D. Wang, H. Lu, Environ. Sci. Technol., 29 (2006).

9. W. Zhang, Study of the alternating pulse electrolysis-ozone-hydrogen peroxidecoordination degrading aniline (Wuhan University of Technology, 2006).

10. Z. Zhou, J. Yao, Z. Pang, Water Purif. Technol., 34 (2015).

11. Z. Zhou, J. Yao, B. Liu, Chem. Bioeng., 34 (2017).

12. Z. Zhou, Y. Yu, Z. Ding, Eur. J. Inorg. Chem., 6 (2018).

13. Y. Shi, H. Meng, H. Yu, J. Univ. Sci. Technol. Beijing, 30 (2008).

14. W. Wang, Fenton-like process of sponge iron/o2 system and degradation of refractory organic compounds (A case study of aniline) (Lanzhou Jiaotong University, 2016). 